\title{
Chemical Synthesis and Expression of the HIV-1 Rev Protein
}

\author{
Peter Siman, ${ }^{[a]}$ Ofrah Blatt, ${ }^{[b]}$ Tal Moyal, $^{[a]}$ Tsafi Danieli, $^{[c]}$ Mario Lebendiker, ${ }^{[c]}$ Hilal A. Lashuel, ${ }^{[d]}$ \\ Assaf Friedler, ${ }^{*[b]}$ and Ashraf Brik ${ }^{*[a]}$
}

\begin{abstract}
The HIV-1 Rev protein is responsible for shuttling partially spliced and unspliced viral mRNA out of the nucleus. This is a crucial step in the HIV-1 lifecycle, thus making Rev an attractive target for the design of anti-HIV drugs. Despite its importance, there is a lack of structural, biophysical, and quantitative information about Rev. This is mainly because of its tendency to undergo self-assembly and aggregation; this makes it very difficult to express and handle. To address this knowledge gap, we have developed two new highly efficient and reproducible methods to prepare Rev in large quantities for biochemical and structural studies: 1) Chemical synthesis by using native chemical ligation coupled with desulfurization. Notably, we have optimized our synthesis to allow for a one-pot approach for the ligation and desulfurization steps; this reduced the
\end{abstract}

number of purification steps and enabled the obtaining of desired protein in excellent yield. Several challenges emerged during the design of this Rev synthesis, such as racemization, reduced solubility, formylation during thioester synthesis, and the necessity for using orthogonal protection during desulfurization; solutions to these problems were found. 2) A new method for expression and purification by using a vector that contained an HLT tag, followed by purification with a $\mathrm{Ni}$ column, a cation exchange column, and gel filtration. Both methods yielded highly pure and folded Rev. The CD spectra of the synthetic and recombinant Rev proteins were identical, and consistent with a predominantly helical structure. These advances should facilitate future studies that aim at a better understanding of the structure and function of the protein.

\section{Introduction}

The HIV-1 Rev protein mediates the nuclear export of viral mRNA, thus enabling formation of new infectious virus particles. ${ }^{[1,2]}$ The $13 \mathrm{kDa}$ Rev protein consists of several motifs that play important roles in its cellular function. The leucine-rich motif (LRM, residues 75-83), located at the $C$ terminus operates as a nuclear export signal (NES). The arginine-rich motif (ARM, residues 34-50) acts as the nuclear-localization signal (NLS) and as a binding site for the Rev response element (RRE), which is present in all incompletely spliced viral mRNAs. ${ }^{[3-6]} \mathrm{Al}-$ though Rev was discovered nearly three decades ago, ${ }^{[7]}$ biochemical and structural studies aimed at understanding the structural and functional aspects of the Rev protein are still limited because of its strong tendency to oligomerize, aggregate, and precipitate..$^{[4,8,9]}$ As a result, the majority of the Rev studies have been performed on peptides derived from the protein sequence, and on Rev conjugates such as RevGFP. ${ }^{[6,10-12]}$ Only very recently was the X-ray structure of this protein solved; however, it was complexed with a specifically engineered monoclonal Fab (fragment antigen-binding) antibody that served as the solubilizing agent. ${ }^{[9]}$ This structure revealed that only the central part of the protein (residues 9-65) is structured, while the rest is intrinsically disordered. Motivated by the important role of Rev in the HIV replication cycle, and its potential as a drug target, ${ }^{[11,13,14]}$ we developed two efficient synthetic and recombinant methods that allow the production of sufficient amounts of highly pure Rev, and provide the flexibility to prepare novel synthetic analogues of Rev for future studies to elucidate its structure-function relationship with spatial and temporal control.

Total chemical synthesis of proteins offers exceptional opportunities for preparing unstable and novel proteins, in high purity and large quantity, for functional and structural analysis. $^{[15,16]}$ Moreover, the polypeptide is often assembled under denaturing conditions, so the functional protein can be achieved by in vitro folding in the appropriate buffer when desired. Native chemical ligation $(\mathrm{NCL})^{[17]}$ is a powerful method to conjugate two unprotected peptides (by thiol-capture followed

[a] P. Siman, ${ }^{+}$T. Moyal, Prof. A. Brik

Department of Chemistry, Ben-Gurion University of the Negev

P.O. Box 653, Beer Sheva, 84105 (Israel)

Fax: (+972) 8-6472943

E-mail:abrik@bgu.ac.il

[b] O. Blatt, ${ }^{+}$Prof. A. Friedler

Institute of Chemistry, The Hebrew University of Jerusalem

Givat Ram, Jerusalem 91904 (Israel)

E-mail:assaf@chem.ch.huji.ac.il

[c] Dr. T. Danieli, Dr. M. Lebendiker

The Protein Expression and Protein Purification Facilities, Wolfson Centre for Applied Structural Biology, The Hebrew University of Jerusalem Safra Campus, Givat Ram, Jerusalem 91904 (Israel)

[d] Prof. H. A. Lashuel

Laboratory of Molecular Neurobiology and Neuroproteomics Swiss Federal Institute of Technology Lausanne (EPFL) FSV-BMI Al 2137.1 Station 15, 1015 Lausanne (Switzerland)

$\left.{ }^{+}\right]$These authors contributed equally to this work.

Supporting information for this article is available on the WWW under http://dx.doi.org/10.1002/cbic.201100033. 
by a spontaneous S-N acyl transfer) to form the polypeptide chain in the native form. Chemical synthesis can be adopted to prepare proteins of $70-200$ residues, ${ }^{[18-20]}$ thus making Rev a suitable target for such an approach. On the other hand, when attempting the chemical synthesis of full-length Rev by applying Cys- $\mathrm{NCL}$, this strategy is challenged by the presence of two native Cys residues at the C-terminus of Rev; these cannot serve as ligation sites, and might require transient protection during NCL synthesis of Rev. As a result, alternative NCL-based strategies were considered for full-length Rev synthesis. One such strategy is the use of ligation junctions that contain thiolmodified residues that can be desulfurized later to give the native structure. This NCL-desulfurization method, since its invention for an Ala junction, ${ }^{[21]}$ has captured the interest of several laboratories, including ours, and enabled performing $\mathrm{NCL}$

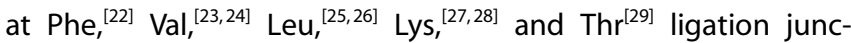
tions. Moreover, this concept has been extended to include sugar-assisted ligation ${ }^{[30,31]}$ for glycopeptide synthesis, and lysine-mediated peptide and protein ubiquitination. ${ }^{[27,32,33]}$

\section{Results and Discussion}

\section{Chemical synthesis of HIV-1 Rev}

In our synthesis strategy for obtaining Rev (Scheme 1) the protein sequence was divided into three fragments: residues 68116 (Rev1), 37-67 (Rev2) and 1-36 (Rev3). In this strategy, the Ala residues at positions 37 and 68 were temporarily replaced with $\mathrm{Cys}^{[21]}$ to allow $\mathrm{NCL}$ between Rev1 and Rev2, and later between Rev2-Rev1 and Rev3. After full assembly of the polypeptide sequence, a desulfurization step ${ }^{[34,35]}$ was employed to convert Cys37 and Cys68 back to their native Ala forms. The two native Cys residues at positions 85 and 89 were masked temporarily with acetamidomethyl (Acm) protecting groups, ${ }^{[36,37]}$ to avoid conversion to Ala residues in the desulfurization step; this was followed by selective Acm-deprotection to afford wild-type Rev protein.

The three peptide precursors, Rev1-3, were synthesized by using Fmoc-SPPS. The Rev1 fragment (49-mer, bearing an $\mathrm{N}$ terminal (ys) was synthesized in $15 \%$ isolated yield. In the cases of the Rev2 and Rev3 thioester fragments, the presence of Ser and Gln, respectively, at the C-termini of the peptides prompted us to prepare these peptide thioesters by applying a side-chain anchoring strategy and Fmoc-SPPS. ${ }^{[38,39]}$ Accordingly, Rev2 was prepared in $25-30 \%$ isolated yield by anchoring commercially available $\mathrm{Fmoc}(\mathrm{Ser})-\mathrm{OAll}$ with boron trifluoride etherate to trichloroacetimidate-activated Wang resin, ${ }^{[40,41]}$ followed by peptide elongation by Fmoc-SPPS (see the Supporting Information). The Rev3 thioester was prepared in similar yield by anchoring Fmoc-(Glu)-OAll on Rink amide resin (Supporting Information). ${ }^{[42-45]}$

We then turned our focus to the synthesis of the full length Rev protein by applying the above-described strategy. We first ligated Rev1 to Rev2 under NCL conditions, followed by conversion of the 1,3-thiazolidine-4-carboxo (Thz) to Cys by using methoxylamine, ${ }^{[46]}$ to give Rev2-Rev1 in $35 \%$ isolated yield for the two steps (Figure 1A and B). Subsequently, Rev2-Rev1
$M^{1} A$ G R S D S $E^{10} \mathrm{E} L I R T V R L I K^{20} L L Y Q S N P P P N^{30} P$ E G TR Q A R R N ${ }^{40} R$ RR RWRERQR R ${ }^{50} Q$ I HSISERIL $L^{60} G T$ YLGR $\underline{\text { SA }} E P^{70} V P L Q L P P L E R^{80} L T L D C N E D C G^{90}$ TS G $T Q G \vee G S P^{100} Q I L \vee E S P T \vee L^{110} E S G T K E^{116}$
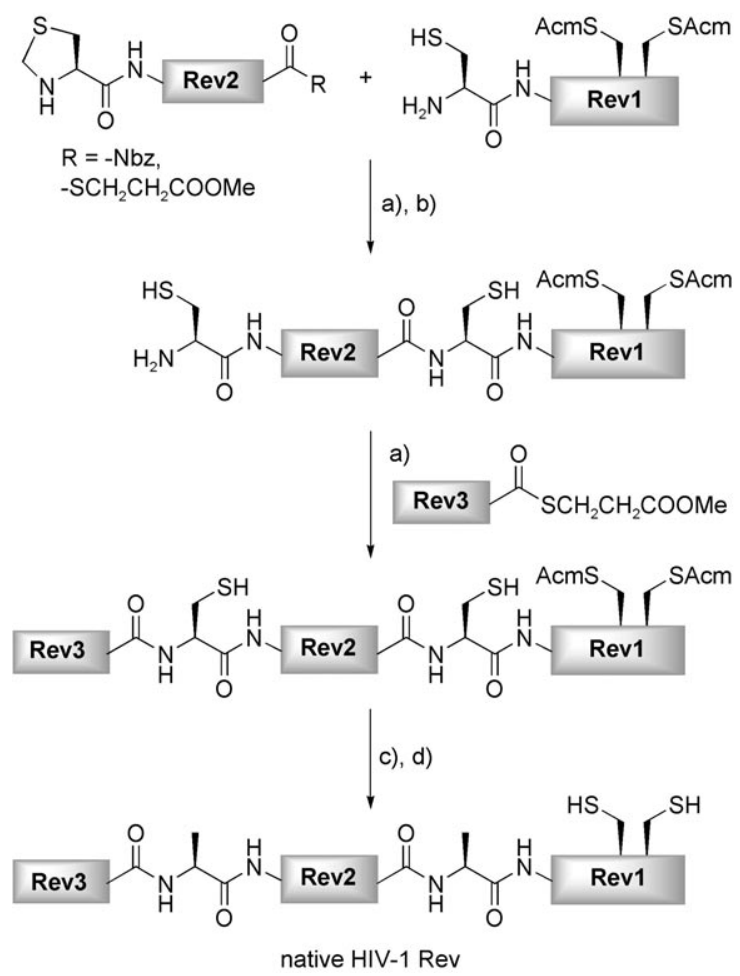

Scheme 1. HIV-1 Rev sequence and NCL-based synthesis strategy (the ligation junctions are highlighted within the sequence). Met 1 was replaced with Nle to avoid oxidation during synthesis and handling. a) NCL, b) Thz-Cys conversion, c) desulfurization, d) Acm removal.

peptide was ligated to Rev3 to give the full length Rev polypeptide in $35 \%$ isolated yield (Figure 1C). We then applied free radical desulfurization conditions ${ }^{[23,34,47]}$ to yield the desired desulfurized product (for native Ala residues) in $60 \%$ isolated yield after $8 \mathrm{~h}$ (Supporting Information). The desulfurized product was then subjected to Acm-removal conditions to unmask the C-terminal Cys residues, and this furnished the desired (native) Rev in $60 \%$ isolated yield. To determine whether this synthetic Rev is able to adopt the native folded-state of the protein, the polypeptide was solubilized in folding buffer (Experimental Section), and its secondary structure was examined by circular dichroism (CD), and compared to that of the recombinant Rev protein. ${ }^{[8]}$ The $C D$ spectrum of the synthetic protein showed less-ordered secondary structure than that of the recombinant protein. ${ }^{[8]}$ Efforts to optimize the folding of the synthetic proteins by changing buffer, temperature, and concentration did not improve these results. We reasoned that our synthesis strategy has some pitfalls, and required further investigation and optimization.

We first suspected that one/both of the C-terminal residues (Ser and Gln) of the thioester peptides had some racemization that might have occurred during the thioester synthesis. However, several studies have reported the presence of just traces 

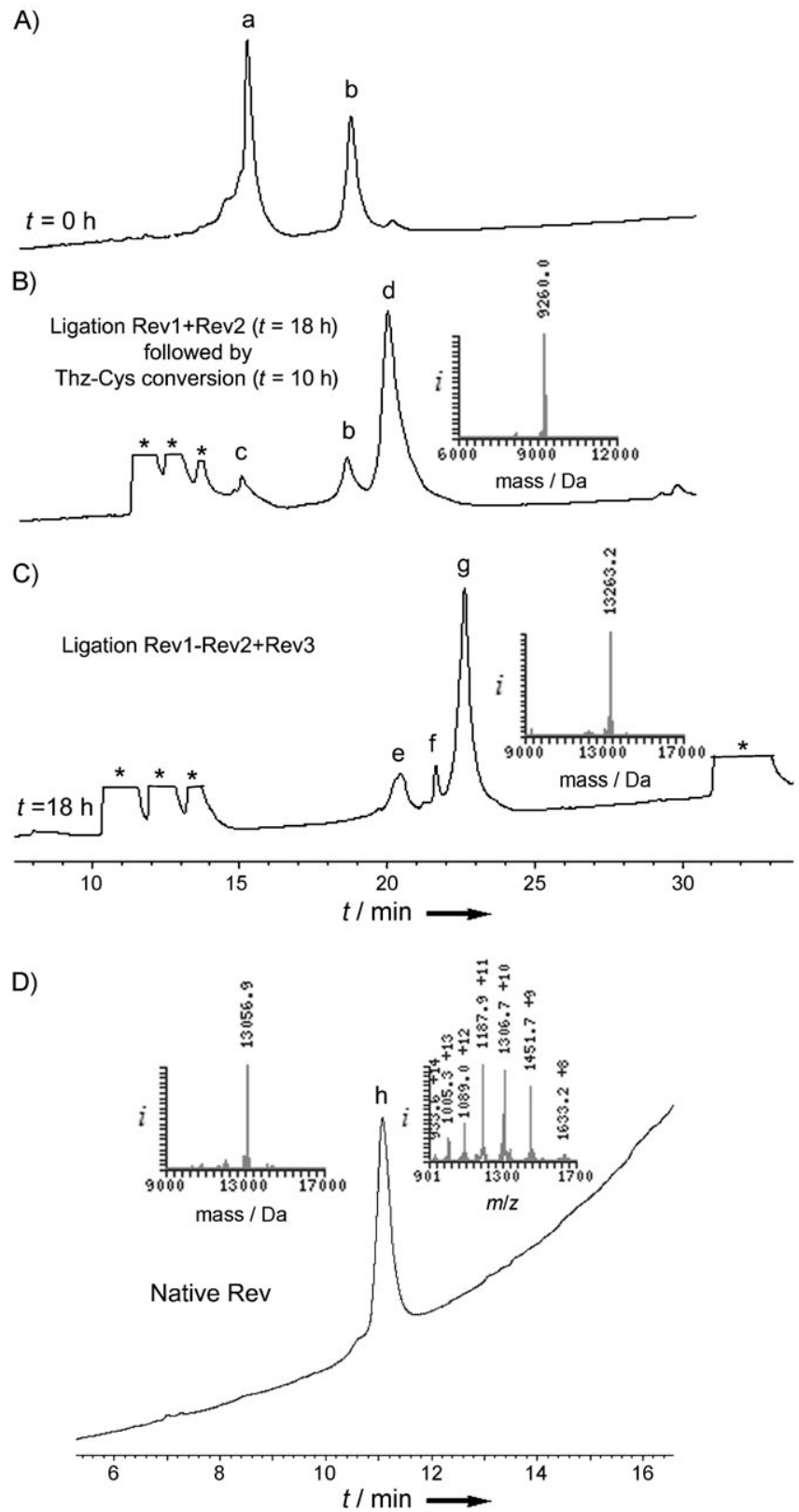

Figure 1. Analytical HPLC monitoring of the synthesis of HIV-1 Rev protein with NCL/orthogonal protection/desulfurization: A) Ligation between Rev1 (1.2 equiv) and Rev2 at 0 h. Peak a: Rev2 thioester, and peak b: Rev1 fragment. B) Ligation between Rev1 and Rev2 after $18 \mathrm{~h}$, followed by Thz to Cys conversion after $10 \mathrm{~h}$. Peak c: hydrolyzed Rev2 (obs.: $3996 \mathrm{Da}$, calcd: 3996 Da), peak b: unreacted Rev1, peak d: ligation product (Rev2-Rev1, obs.: 9260.0 Da, calcd 9259.1 Da). Inset: deconvoluted ESI-MS. C) Ligation reaction between Rev2-Rev1 and Rev3 (1.2 equiv) after $18 \mathrm{~h}$. Peak e: hydrolyzed Rev3 (obs.: 4021 Da, calcd: 4021 Da), Peakf: Rev3 after thiol exchange with benzyl mercaptan (obs.: $4127 \mathrm{Da}$, calcd: $4128 \mathrm{Da}$ ), peak g: ligation product Rev3-Rev2-Rev1 (obs.: 13263.2 Da, calcd 13262.5 Da). Inset: deconvoluted ESI-MS. *: thiol additives. D) Acm deprotection reaction of Rev3Rev2-Rev1. Peak h: HIV-1 Rev(1-116) (obs.: 13056.9 Da (insets), calcd: 13056.7 Da)

of racemization at GIn thioesters ${ }^{[38,39,42-45,48]}$ when using protocols similar to those used in our study (PyBOP-coupling conditions); this rules out racemization at the Gln residue of Rev3. On the other hand, the level of racemization in the case of the
C-terminal Ser thioester, which we prepared by using $\mathrm{BF}_{3}$.etherate on trichloroacetimidate activated Wang resin, has not been investigated. ${ }^{[40,41]}$ Therefore, we sought to investigate whether racemization had occurred at the C-terminal Ser moiety of the Rev2 thioester, as this might interfere with the folding of the protein. Indeed, careful investigation by HPLC analysis revealed two peaks that eluted at different retention times: these corresponded to Rev2 benzyl mercaptan/thioester with a 7:3 ratio (Supporting Information).

Based on the above observations we modified our synthesis strategy by including a racemization-free $\mathrm{N}$-acyl urea method $^{[49]}$ to give Rev2-Nbz in 30\% isolated yield (Supporting Information). Notably, after assembly of the Rev protein (with Rev2-Nbz), the CD analysis revealed a spectrum that is consistent with a predominantly helical protein, and that this was virtually identical to that of the recombinant protein (Figure 2). Western blot analysis of synthesized Rev showed that the protein is recognized by an anti-Rev antibody (Rat anti-Rev, Experimental Section).

Notably, we were unable to prepare the Rev2-Nbz with DCM as the solvent for the activation step with $p$-nitrophenylchloroformate, despite efficient SPPS synthesis of this fragment before this step (Supporting Information). We reasoned that this peptide undergoes severe aggregation in DCM, and that this renders the activation step very challenging. Thus we examined DMF, which is known to be a better solvent for long peptides, as an alternative solvent. The activation step was successfully achieved. However, we observed an additional $28 \mathrm{Da}$ in its mass; this presumably correlates with the incorporation of a formyl group into this peptide. Peptide treatment with methyl 3-mercaptopropionate led to elimination of the $\mathrm{N}$-acylurea moiety, to give a Rev2 thioester with the desired mass (Supporting Information).

This also supports the hypothesis that the additional mass was linked to the $\mathrm{N}$-acylurea moiety rather than to the peptide. We concluded that the formylation had occurred on the $\mathrm{N}$ acylurea moiety by a Vilsmeier-Haack reaction, due to the use of $p$-nitrophenylchloroformate in DMF, thus generating the active Vilsmeier reagent (Scheme 2). ${ }^{[50,51]}$ Further analysis of the formylation site on a short model-peptide (Leu-Leu-Nbz) revealed that this modification had occurred on the free nitrogen of the imidazolinone moiety, as indicated by ${ }^{1} \mathrm{H}$ and ${ }^{13} \mathrm{C}$ NMR analysis (Supporting Information): the three aromatic protons were intact after formylation, along with the presence of a formyl proton at $8.5 \mathrm{ppm}$.

\section{One-pot synthesis of HIV-1 Rev}

The above-described strategy required four purification steps to yield the final Rev protein in $6-7 \%$ total isolated yield. We then tested a one-pot strategy for synthesis up to the Acm removal step. This had two ligation reactions: Thz-Cys conversion, and a desulfurization step. To allow desulfurization directly after the ligation, and Thz-Cys conversion, we first examined the use of different thiol-additives as we realized that such a thiol should aid several tasks. Firstly, it should activate the alkyl thioester to permit an efficient NCL step; secondly, it reduces 

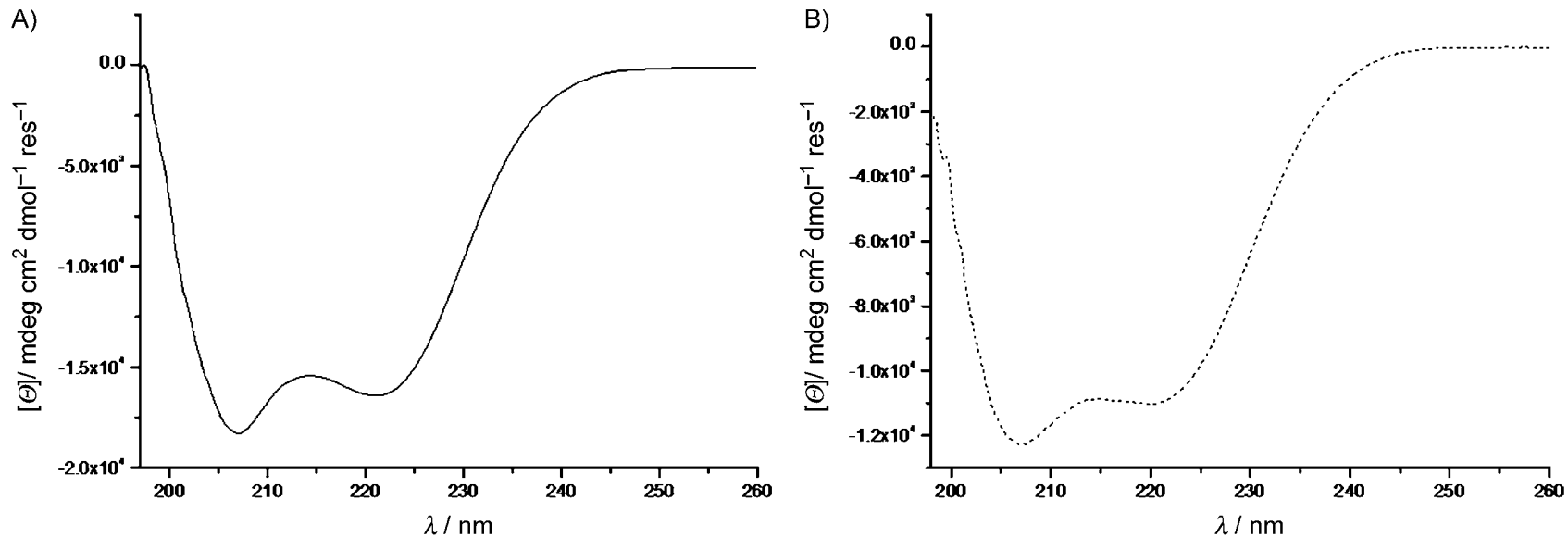

Figure 2. CD spectra of A) recombinant and B) synthesized Rev. Both spectra show typical minima at 208 and $222 \mathrm{~nm}$, consistent with a predominantly helical structure.

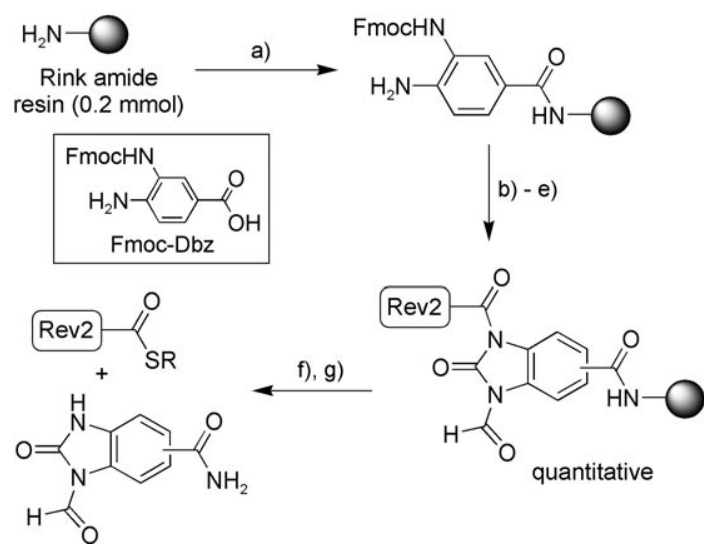

Scheme 2. Formylation of Rev2-Nbz by the Vilsmeier-Haack reaction during the activation step by using $p$-nitrophenylchloroformate in DMF. a) FmocDbz, HBTU/HOBt/DIEA, DMF; b) 20\% piperidine; c) Fmoc SPPS; d) $p$-nitrophenylchloroformate; e) 0.5 M DIEA, DMF; f) cleavage (TFA,TIS, $\mathrm{H}_{2} \mathrm{O}$ ); g) R-SH.

the possibility of disulfide-bond formation, and thus maintains a free $\mathrm{N}$-terminal Cys; and thirdly, it serves as the hydrogen donor ${ }^{[34,47]}$ (instead of tert-butylmercaptan) in the desulfurization reaction. After examining several thiol additives, including benzyl mercaptan, thiophenol, MPAA, and MESNa, in the desulfurization reaction on a model peptide (CLYRAG), we found that the MESNa gave the best results and allowed rapid and efficient desulfurization (Supporting Information). All other thiols, although affording ligation at a faster rate, failed to allow one-pot desulfurization in model ligations with CLYRAG and Thz-LYRAG-thioester (Supporting Information). Based on these results, we then carried out all the synthesis steps up to the Acm removal (Scheme 1) as a one-pot synthesis, followed by a purification and final deprotection to give the Rev protein in $15 \%$ overall isolated yield (Supporting Information). These results testify to the advantages of carrying out sequential ligation and desulfurization in a one-pot manner, to increase the yield of the target protein. ${ }^{[46,52]}$

\section{Expression of HIV-1 Rev}

In parallel to our synthesis strategy, we developed a new protocol for the expression and purification of recombinant Rev to increase solubility, facilitate the purification and obtain higher expression yield. We used a modified pET22 vector ( $p E T-H L T)$ that contained a $\mathrm{His}_{6}$-tag for IMAC purification, a Lipoyl domain for increasing solubility and expression, and a TEV protease cleavage site. The gene for Rev (HXB2 isolate) was amplified from pCsRevsg143 by PCR, and subcloned into pET-HLT. The protein was expressed in BL21-CodonPlus-RIL, and then purified by using three sequential chromatographic purification procedures: affinity purification on a Ni-Sepharose column, followed by cleavage by TEV protease; purification on a cation-exchange column; and final purification on a gel filtration column (Experimental Section). This procedure afforded a folded (Figure 2), highly pure, and homogeneous protein (single peak on the Superdex 75 gel filtration column, Figure 3 C). SDS-PAGE and Western blot analysis showed a single band with an apparent $\mathrm{Mw}$ of $20 \mathrm{kDa}$ (Figure 3D). By using this procedure, we were able to achieve a final yield of $32 \mathrm{mg}$ of pure native Rev from $1 \mathrm{~L}$ culture, superior to that in a previous report $\left(9 \mathrm{mg} \mathrm{L}^{-1}\right) \cdot{ }^{[53]}$

\section{Conclusions}

In summary, we present two novel and efficient methods of preparing the HIV-1 Rev protein in high quantity and purity. In the synthesis approach, we applied different methods to synthesize the thioester fragments, and revealed their advantages and disadvantages. An important aspect of our synthesis is the use of the one-pot approach to include the desulfurization step; this reduces the number of purification steps and significantly increases the synthesis yield. Having these synthesis tools in hand, we plan to study the effect of post-translational modifications $s^{[54-56]}$ on the function and structure of the Rev protein, along with introducing chemical switches ${ }^{[57,58]}$ to control Rev folding and self-assembly, to better understand these processes on the function of Rev protein. ${ }^{[4,53,59]}$ 

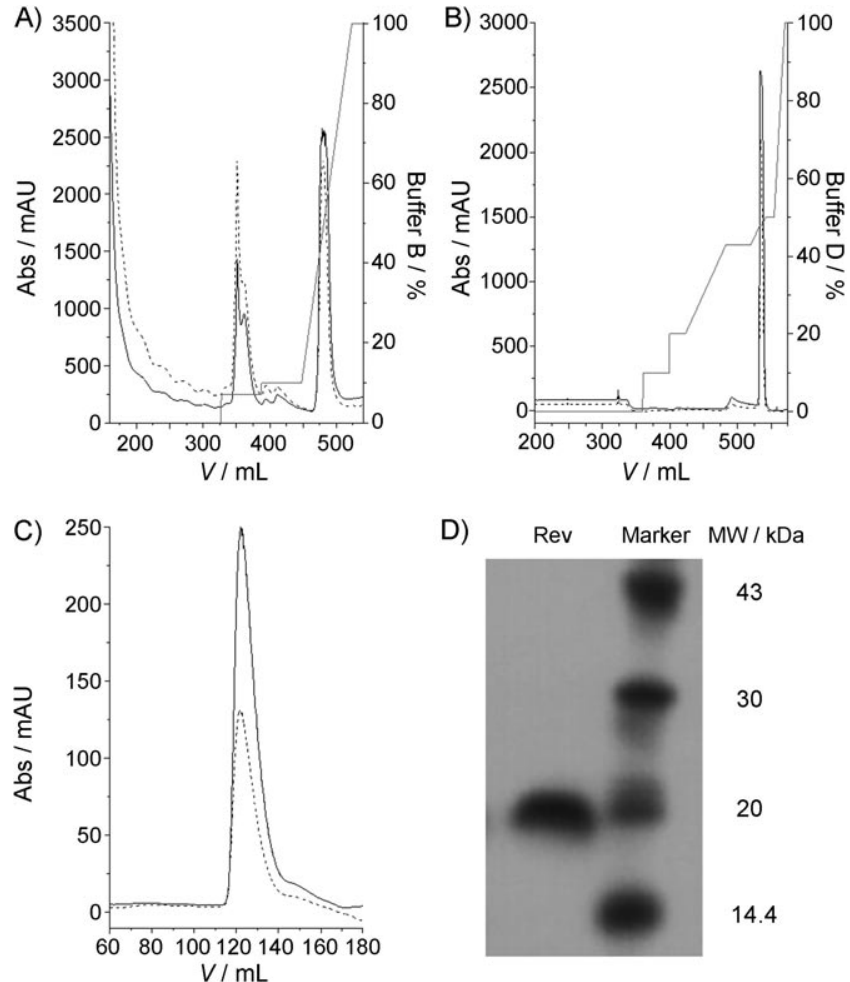

D)

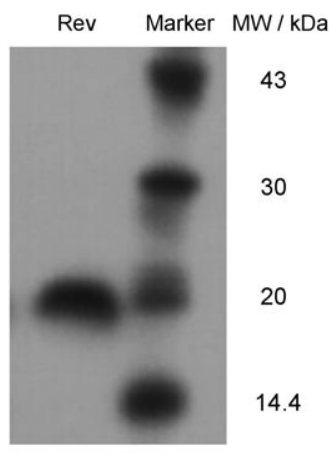

Figure 3. Purification of recombinant Rev. UV absorbance chromatograms at $280 \mathrm{~nm}(-)$ and $260 \mathrm{~nm}(----)$ of HLT-Rev following serial purification by A) Ni column, B) cation exchange, and C) gel filtration. D) SDS-PAGE of recombinant Rev showing purity of the protein preparation.

Using our recombinant expression and purification approaches, we were able to achieve a yield of $32 \mathrm{mg}$ pure protein per liter of medium, compared to the $9 \mathrm{mg}$ per liter previously reported. ${ }^{[53]}$ The purified protein is stable (it does not aggregate) at concentrations up to $200 \mu \mathrm{M}$ in the absence of stabilizing additives. Higher concentrations were reached when crystallization of the protein in complex was studied; ${ }^{[9]}$ however, our purification protocol is the first for obtaining high concentrations of free native soluble Rev in solution with no additives. The recombinant protein was also essential in the development of our optimal chemical synthesis of Rev, and enabled us to improve the synthesis and to develop a method for transferring the chemically synthesized protein to a buffer suitable for biological experiments. Both new methods serve as a basis for further research into Rev, and will lead to a better understating of virus activity and regulation.

\section{Experimental Section}

\section{Material and methods}

SPPS: Peptide synthesis was carried out in syringes equipped with teflon filters (Torviq, Niles, MI), or by using a CS336X peptide synthesizer (CS Bio Co, Menlo Park, CA). Except where described differently, all reactions were carried out at room temperature. Resins, protected amino acids, and HBTU were purchased from Novabiochem. DMF was purchased in biotech grade.
Peptide analysis: Analytical HPLC, for monitoring progress of reactions and peptide purity, was performed on a SpectraSYSTEM P4000 (Thermo Scientific) with a Jupiter C5 (Phenonenex, Torrance, CA) analytical column $(5 \mu \mathrm{m}, \mathrm{C} 18 / \mathrm{C} 4,300 \AA, 150 \times 4.6 \mathrm{~mm}$, $1.2 \mathrm{~mL} \mathrm{~min}^{-1}$ ). Preparative HPLC was performed on a Waters 2489/ 2535 instrument with a preparative column (Jupiter 10 micron, $\mathrm{C} 18 / \mathrm{C} 4,300 \AA, 250 \times 21.2 \mathrm{~mm}, 25 \mathrm{~mL} \mathrm{~min}^{-1}$ ). Mass spectrometry analysis was carried out by using an LCQ Fleet lon Trap (Thermo Scientific).

Synthesis of Rev1: The synthesis was carried out by using Fmoc SPPS on Rink amide resin $\left(0.2 \mathrm{mmolg}^{-1}, 0.1 \mathrm{mmol}\right.$ scale). The synthesis was performed on a $\mathrm{C} 5 \mathrm{BIO}$ peptide synthesizer in the presence of amino acid (AA, 4 equiv), DIEA (8 equiv) and HBTU/HOBt (4 equiv) for the initial loading of the resin. The coupling was left for $1 \mathrm{~h}$, and Fmoc-deprotection was achieved by using $20 \%$ piperidine with $5 / 10 / 5$ min cycles.

Cleavage from the resin: A mixture of TFA, triisopropylsilane (TIS), and water (95:2.5:2.5) was added to the dried peptide-resin, and the reaction mixture was shaken for $2 \mathrm{~h}$ at RT. The resin was removed by filtration, and was washed with TFA $(2 \times 2 \mathrm{~mL})$. To precipitate the peptide, the combined filtrate was added drop-wise to a tenfold volume of cold ether, followed by centrifugation, decanting of ether, and desolvation of residues in acetonitrile/water for the HPLC purification step.

Synthesis of Rev2 thioester: The synthesis was started by swelling trichloroacetimidate Wang resin $(133 \mathrm{mg}, 0.1 \mathrm{mmol})$ with DCM for $30 \mathrm{~min}$. The resin was washed with dry THF several times, followed by the addition of Fmoc-Ser-OAll $(110 \mathrm{mg}, 0.30 \mathrm{mmol})$ dissolved in dry THF ( $2 \mathrm{~mL})$. After $2 \mathrm{~min}$, boron trifluoride diethyl etherate $(6 \mu \mathrm{L}$, $0.05 \mathrm{mmol}$ ) was added, stirred briefly, and left for $1 \mathrm{~h}$. Subsequently, methanol $(0.2 \mathrm{~mL})$ was added for capping the unreacted sites, and the reaction was allowed to proceed for a further $5 \mathrm{~min}$, then washed several times with THF and DMF. SPPS for the remaining amino acids was achieved by using a peptide synthesizer as described above.

Allyl deprotection: the resin was swollen with DCM for $10 \mathrm{~min}$, followed by treatment with $\mathrm{N}$-methylaniline (NMA; $110 \mu \mathrm{L}, 1 \mathrm{mmol}$ ) dissolved in dry DCM $(0.5 \mathrm{~mL})$, followed by the addition of $\mathrm{Pd}^{0}$ ( $25 \mathrm{mg}, 0.02 \mathrm{mmol}$ in $1.5 \mathrm{~mL} \mathrm{DCM}$ ) and left to shake for $30 \mathrm{~min}$. Subsequently, the resin was washed several times with DCM. The above procedure was repeated twice, followed by a final DMF wash.

Thioesterification: The resin was treated with methyl 3-mercaptopropionate (20 equiv, $111 \mu \mathrm{L}, 1 \mathrm{mmol}$, dissolved in $0.5 \mathrm{~mL} \mathrm{DMF}$ ), ByBOP (3 equiv, $78 \mathrm{mg}, 0.15 \mathrm{mmol}$ ) and DIEA (3 equiv, $26 \mu \mathrm{L}$, $0.15 \mathrm{mmol}$, dissolved in $0.5 \mathrm{~mL}$ DMF). The reaction was followed by analytical cleavage from the resin (complete coupling was indicated after $12 \mathrm{~h}$ ). Cleavage and purification were carried out as described for Rev1.

Synthesis of Rev3 thioester by side-chain anchoring: The synthesis was carried out by using Fmoc-Glu-OAll coupled to Rink amide resin $\left(0.6 \mathrm{mmolg}^{-1}, 0.1 \mathrm{mmol}\right.$ scale). The peptide synthesis was performed on a peptide synthesizer as described above. The coupling was left for $1 \mathrm{~h}$, and Fmoc-deprotection was achieved by using $20 \%$ piperidine with 5/10/5 min cycles. The deallylation and thioesterification steps were preformed as described for the synthesis of the Rev2 thioester. Cleavage and purification were carried out as described for Rev1.

Synthesis of Rev2-Nbz: The synthesis was carried out by using the $\mathrm{N}$-acylurea method (Scheme 2) on Rink amide resin $\left(0.6 \mathrm{mmolg}^{-1}\right.$, 
$0.1 \mathrm{mmol}$ scale). Amino acids and HOBt/HBTU were used in fourfold excess of the initial loading of the resin. DIEA was used in eightfold excess. The first two amino acids were double coupled for $1 \mathrm{~h}$. Fmoc deprotection was achieved by treatment of the resin with $20 \%$ piperidine $(3 \times 3 \mathrm{~min})$. The remaining amino acids were coupled by using a peptide synthesizer as described above.

On-resin activation: After completion of peptide synthesis, the resin was washed with DMF, and a solution of $p$-nitrophenylchloroformate ( $100 \mathrm{mg}, 5$ equiv. in $10 \mathrm{~mL}$ DMF) was then added and shaken for $1 \mathrm{~h}$ at RT. The resin was washed with DMF $(3 \times 5 \mathrm{~mL})$. Following these steps, a solution of DIEA ( $0.5 \mathrm{M}$ in $5 \mathrm{~mL}$ DMF) was added, and the mixture was shaken for an additional $30 \mathrm{~min}$. The resin was washed with DMF $(3 \times 5 \mathrm{~mL})$. Cleavage and purification were carried out as described for Rev 1 .

Synthesis of the peptide LeuLeu-Nbz: the synthesis and activation were carried out as for Rev2-Nbz described above.

\section{Rev assembly by NCL}

Ligation of Rev1 and Rev2: Rev1 $(10.0 \mathrm{mg}, 1.9 \mu \mathrm{mol})$ and Rev2 $(8.8 \mathrm{mg}, 2.08 \mu \mathrm{mol})$ were dissolved in $\mathrm{Gn} \cdot \mathrm{HCl}(950 \mu \mathrm{L}, 6 \mathrm{M})$ with phosphate buffer $(200 \mathrm{~mm}, \mathrm{pH} 7.0)$. Benzylmercaptan $(19 \mu \mathrm{L})$ and thiophenol $(19 \mu \mathrm{L})$ were added, and the solution was incubated at $37^{\circ} \mathrm{C}$. The progress of reaction was monitored by using an analytical C4 column with a gradient of $5-50 \%$ B over 40 min.

Thz to Cys conversion: Following ligation, the reaction mixture was diluted to $1 \mathrm{~mm}$ in a solution of methoxylamine $(0.4 \mathrm{M}$, containing 30 equiv. TCEP, $\mathrm{pH} 4$ ) and incubated at $37^{\circ} \mathrm{C}$. The progress of the reaction was monitored by using an analytical $C 4$ column with a gradient of $5-50 \%$ B over 40 min. Purification and lyophilization afforded the desired product in $35 \%$ yield $(6.1 \mathrm{mg})$.

Ligation of Rev2-Rev1 to Rev3: Rev2-Rev1 (6.1 mg, $0.65 \mu \mathrm{mol})$ and Rev3 $(3.0 \mathrm{mg}, 0.72 \mu \mathrm{mol})$ were dissolved in $\mathrm{Gn} \cdot \mathrm{HCl}(280 \mu \mathrm{L}, 6 \mathrm{M})$ with phosphate buffer $(200 \mathrm{~mm}, \mathrm{pH} 7.0)$. Benzylmercaptan $(5.6 \mu \mathrm{L})$ and thiophenol $(5.6 \mu \mathrm{L})$ were added, and the solution was incubated at $37^{\circ} \mathrm{C}$. The progress of reaction was monitored by using an analytical C4 column with a gradient of $5-50 \%$ B over $40 \mathrm{~min}$. Purification and lyophilization afforded the desired product in $35 \%$ yield (3.0 mg).

Desulfurization of Rev3-Rev2-Rev1: The purified ligation product was dissolved to a concentration of $2 \mathrm{~mm}$ in $\mathrm{Gn} \cdot \mathrm{HCl}(6 \mathrm{M})$ with phosphate buffer ( $200 \mathrm{~mm}, \mathrm{pH} 7.4)$, and purged under argon. To this solution, the same volume of $\operatorname{TCEP}(0.5 \mathrm{M})$ was added, followed by the addition of tert-butyl mercaptan $(4 \%, v / v)$ and of the radical initiator VA-044 $(0.1 \mathrm{M}, 8 \%, v / v$ in $\mathrm{Gn} \cdot \mathrm{HCl})$, and incubated at $37^{\circ} \mathrm{C}$ for $12 \mathrm{~h}$. The progress of reaction was monitored by using an analytical C18 column with a gradient of $5-55 \%$ B over $30 \mathrm{~min}$. Purification and lyophilization afforded the desired product in $60 \%$ yield (1.8 mg).

Acm deprotection: Desulfurized Rev3-Rev2-Rev1 was dissolved in of $10 \% \mathrm{AcOH}(160 \mu \mathrm{L}, \mathrm{pH} 4.0)$ containing 30 equiv. $\mathrm{Hg}(\mathrm{OAc})_{2}$. The reaction mixture was mixed well and left at room temperature for $3 \mathrm{~h}$. Following this, DTT (120 equiv) was added, and the mixture was allowed to react for $24 \mathrm{~h}$. The black precipitate was removed and the supernatant was collected for HPLC purification. The progress of reaction was monitored by using analytical C18 column with a gradient of $5-55 \%$ B over 30 min. Purification and lyophilization afforded the desired product in $60 \%$ yield $(1 \mathrm{mg})$.

One-pot synthesis of Rev protein: Rev $1(5.0 \mathrm{mg}, 0.95 \mu \mathrm{mol})$ and Rev2 $(4.4 \mathrm{mg}, 1.04 \mu \mathrm{mol})$ were dissolved in of $\mathrm{Gn} \cdot \mathrm{HCl}(6 \mathrm{M}, 150 \mu \mathrm{L})$ with phosphate buffer $(200 \mathrm{~mm}, \mathrm{pH} 7.0)$. A solution of MESNa $(5 \%$, $w / v)$ was added, and the solution was incubated at $37^{\circ} \mathrm{C}$. After completion of the ligation, the reaction mixture was diluted to $3 \mathrm{~mm}$ in methoxylamine solution $(150 \mu \mathrm{L}, 0.4 \mathrm{M}, \mathrm{pH} 4$, containing 30 equiv. TCEP) and incubated at $37^{\circ} \mathrm{C}$. Upon completion, the $\mathrm{pH}$ of the reaction mixture was adjusted to approximately $\mathrm{pH} 7$ with $\mathrm{NaOH}(1 \mathrm{M})$, followed by the addition of Rev3 $(2.7 \mathrm{mg}, 0.66 \mu \mathrm{mol})$. The reaction was left at $37^{\circ} \mathrm{C}$ for an additional $24 \mathrm{~h}$. Upon completion of the second ligation, VA-044 (4 equiv.) was added. In all these steps, the progress of different reaction steps were monitored by using an analytical C4 column with a gradient of $5-50 \%$ B over $30 \mathrm{~min}$. Purification and lyophilization steps afforded the desired product in $25 \%$ yield $(3.3 \mathrm{mg})$.

\section{Constructing the plasmid}

The gene for the HXB2 isolate Rev was amplified from pCsRevsg143 plasmid (kindly donated by Prof. Dr. Ruth BrackWerner, German Research Center for Environmental Health, Munich, Germany) by using PCR with the following oligonucleotides: GTATACCGgaattcGCAGGAAGAAGCGGAGACAGC (forward primer, EcoRI restriction site underlined) and CTAGTTTAgcggccgcTTACTCTTTAGTTCCTGACTCGAGTACTGTAGG (reverse primer, Not1 site). Following digestion of the PCR product and PET-HLT with Notl and EcoRl, the Rev gene was ligated into the pET-HLT plasmid by using T4 DNA ligase (Takara, Shiga, Japan). The ligated vector was transformed into $\mathrm{DH} 5 \alpha$ bacterial strain, and the resulting colonies were screened by PCR and verified by sequencing (Center for Genomic technologies, Hebrew University). As a result of the subcloning of the Rev into the pET-HLT, a linker of six residues (GGSGIQ) remained between the TEV recognition site and the Rev gene. Upon cleavage of the protein product by TEV protease, the Rev protein included a GGSGIQ tail at the $\mathrm{N}$ terminus (Figure 4).

$M^{1}$ H H H H HS G $A^{10} F$ EF KLPDIG $E^{20}$ G I HEGEIVK $W^{30} F$ VKP GDEVNE $E^{40} D D V L C E V Q N D^{50} K A V V E I P S P V^{60} K G K V L E I L$ V ${ }^{70} E G T V A T V G Q T^{80} L I T L D A P G Y E^{90} N M T T G S D T G E^{100} N$ LYFQGGSGI $\left.\right|^{110} Q A G R S G D S D E^{120} E L I R T V R L I K^{130} L L Y Q S$ NPPPN ${ }^{140} P E G T R Q A R R N^{150} R R R R W R E R Q R^{160} Q$ IHSISE $R$ I L ${ }^{170} \mathrm{G} T Y L G R S A E P^{180} V P L Q L P P L E R^{190} L T L D C N E D C G^{200}$ TS GTQGVGS $P^{210} Q$ I L VESPTV L ${ }^{220} E S G T K E^{226}$

Figure 4. Rev (HXB2 isolate) sequence with HLT-tag. Residues 1-111: HLT fusion tag. Residues 100-107: TEV protease cleavage site. Residues 106-111: additional residues resulting from cloning. Residues 112-226: sequence of Rev.

Production of Recombinant Rev: The pET-HLT-Rev construct was transformed into BL21CodonPlus RIL (Stratagene). Cells were then plated on ampicillin-selective plates, and incubated for $16 \mathrm{~h}$. The next day, colonies were transferred to $2 \times Y T$ medium $(3 \mathrm{~mL})$ containing of ampicillin $\left(33 \mathrm{mg} \mathrm{L}^{-1}\right)$, and the culture was grown for an additional $16 \mathrm{~h}$ in an incubator-shaker at $37^{\circ} \mathrm{C}$. The $16 \mathrm{~h}$ growth was then transferred (1:100) into an Erlenmeyer flask containing $2 \times$ YT medium supplemented with antibiotics, and the culture was grown at $37^{\circ} \mathrm{C}$ until $\mathrm{OD}_{600}$ reached 0.7 . The flask was transferred into a $17 \mathrm{C}$ shaker, and induced with IPTG $(0.4 \mathrm{~mm})$. Cells were harvested $16 \mathrm{~h}$ post-induction. Cells were collected by centrifugation and stored at $-70^{\circ} \mathrm{C}$. The bacterial pellet was then lysed by using a microfluidizer (M-110 EHIS; Microfluidics, Newton, MA) and the samples were analyzed on SDS-PAGE and by Western blot, with anti-Rev antibody.

Recombinant Rev purification: Cell pellets from $1.5 \mathrm{~L}$ cultures were thawed on ice and suspended in buffer A ( $\mathrm{NaPi}(25 \mathrm{~mm}$, $\mathrm{pH}$ 7.4), $\mathrm{NaCl}(500 \mathrm{~mm}), \beta \mathrm{Me}(2 \mathrm{~mm})$, and imidazole (10 mм)), sup- 
plemented with $\mathrm{MgCl}_{2}(10 \mathrm{~mm})$, PMSF $(1 \mathrm{~mm})$, lysozyme $\left(0.2 \mathrm{mg} \mathrm{mL}^{-1}\right)$, and DNaseA $\left(50 \mu \mathrm{g} \mathrm{mL}^{-1}\right)$. Cells were disrupted mechanically by using a microfluidizer. The soluble supernatant was separated from the insoluble pellet by centrifugation $(20000 \mathrm{~g}$, $20 \mathrm{~min}, 4{ }^{\circ} \mathrm{C}$ ) and filtered. Chromatography was performed by using the AKTA Explorer FPLC system (GE Healthcare Bio-Sciences $A B$, Uppsala, Sweden). Supernatant was loaded on a Ni-Sepharose FF column (GE Healthcare) pre-equilibrated with buffer A, and extensively washed. Protein was eluted from the affinity column by gradually increased imidazole concentration (up to $250 \mathrm{mM}$ ). HLTRev fractions were pooled according to their molecular weight on SDS-PAGE separation, and incubated overnight with TEV protease at a 1:20 molar ratio (TEV:HLT-Rev) at $4{ }^{\circ} \mathrm{C}$ ). After incubation, the cleaved protein was diluted (1:7) in buffer $\mathrm{C}(\mathrm{NaPi}(25 \mathrm{~mm}, \mathrm{pH} 7.4)$, $\mathrm{NaCl}(50 \mathrm{~mm}), 10 \%$ glycerol, and $\beta \mathrm{Me}(2 \mathrm{~mm}))$ in order to reduce conductivity before loading on an $8 \mathrm{~mL}$ Resource $30 \mathrm{~S}$ cation exchange column (GE Healthcare). Column was eluted with a composite $\mathrm{NaCl}$ gradient, and the digested Rev eluted at $\sim 0.5 \mathrm{M} \mathrm{NaCl}$ in buffer $\mathrm{C}$. To further increase the purity of the protein, an additional purification step was performed by using a $200 \mathrm{~mL}(95 \times 1.6 \mathrm{~cm})$ gel filtration Superdex 75 column (GE Healthcare), pre-equilibrated in the final storage buffer ( $\mathrm{NaPi}(50 \mathrm{~mm}), \mathrm{NaCl}(500 \mathrm{~mm}), 10 \%$ glycerol, DTT (1 mM), and $0.02 \% \mathrm{NaN}_{3}$. Rev-containing fractions were pooled, quantified by spectroscopy absorbance at $280 \mathrm{~nm}$, concentrated to $200 \mu \mathrm{m}$, aliquoted, and stored at $-80^{\circ} \mathrm{C}$ after fast freezing.

CD: $C D$ spectra were recorded by using a J-810 spectropolarimeter (Jasco) in a $0.1 \mathrm{~cm}$ quartz cuvette. Far-UV CD spectra were collected over $190-260 \mathrm{~nm}$ at $4{ }^{\circ} \mathrm{C}$. The synthetic protein was refolded by using the following buffer: $\mathrm{NaPi}(50 \mathrm{~mm}), \mathrm{NaCl}(500 \mathrm{~mm}), 10 \%$ glycerol, DTT $(1 \mathrm{~mm})$ and $0.02 \% \mathrm{NaN}_{3}$. Protein was obtained at $50 \mu \mathrm{m}$ final concentration.

Western blot: After SDS-PAGE, samples were transferred onto a cellulose nitrate membrane. The membrane was blocked for $1 \mathrm{~h}$ in PBS containing $1 \%$ non-fat milk powder, 3\% BSA, 18\% Glucose, $10 \%$ glycerol and $0.5 \%$ Tween-20. The cellulose membrane was then incubated in Ab buffer (PBS buffer containing $5 \%$ non-fat dried milk, $0.05 \%$ Tween-20) with the primary antibody, rat antiRev Ab (1:50, kindly donated by Dr. Brack-Werner, German Research Center for Environmental Health, Munich, Germany). After three washes with TBST (Tris. $\mathrm{HCl}(10 \mathrm{~mm}, \mathrm{pH} 8.0), \mathrm{NaCl}(150 \mathrm{~mm})$, and $0.01 \%$ Tween-20), the membrane was incubated once more for $1 \mathrm{~h}$ in Ab buffer with the secondary antibody, HRP-conjugated donkey anti-rat Ab (1:1000, Jackson ImmunoResearch Europe Ltd., Suffolk, UK). The membrane was then washed again with TBST and the protein bands were visualized by using chemical luminescence with luminol.

\section{Acknowledgements}

This work was supported by the Human Frontier Science Program (A.B. and H.A.L.). A.F. is supported by a starting grant from the European Research Council under the European Community's Seventh Framework Programme (FP7/2007-2013)/ERC Grant agreement $n^{\circ} 203413$.

Keywords: desulfurization - HIV-1 Rev protein - protein expression - solid-phase synthesis - Vilsmeier-Haack reaction
[1] S. K. Arya, C. Guo, S. F. Josephs, F. Wong-Staal, Science 1985, 229, 6973.

[2] J. Sodroski, R. Patarca, C. Rosen, F. Wong-Staal, W. Haseltine, Science $1985,229,74-77$

[3] S. Heaphy, J. T. Finch, M. J. Gait, J. Karn, M. Singh, Proc. Natl. Acad. Sci. USA 1991, 88, 7366-7370.

[4] P. T. Wingfield, S. J. Stahl, M. A. Payton, S. Venkatesan, M. Misra, A. C. Steven, Biochemistry 1991, 30, 7527-7534.

[5] J. Kjems, B. J. Calnan, A. D. Frankel, P. A. Sharp, EMBO J. 1992, 11, 11191129.

[6] S. L. Thomas, J. Hauber, G. Casari, Protein Eng. 1997, 10, 103-107.

[7] V. W. Pollard, M. H. Malim, Annu. Rev. Microbiol. 1998, 52, 491 - 532.

[8] T. J. Daly, J. R. Rusche, T. E. Maione, A. D. Frankel, Biochemistry 1990, 29, $9791-9794$.

[9] M. A. DiMattia, N. R. Watts, S. J. Stahl, C. Rader, P. T. Wingfield, D. I. Stuart, A. C. Steven, J. M. Grimes, Proc. Natl. Acad. Sci. USA 2010, 107, $5810-5814$.

[10] J. Rosenbluh, Z. Hayouka, S. Loya, A. Levin, A. Armon-Omer, E. Britan, A. Hizi, M. Kotler, A. Friedler, A. Loyter, J. Biol. Chem. 2007, 282, $15743-$ 15753.

[11] Z. Hayouka, J. Rosenbluh, A. Levin, M. Maes, A. Loyter, A. Friedler, Biopolymers 2008, 90, $481-487$.

[12] J. Lee, D. G. Lee, FEBS Lett. 2009, 583, 1544-1547.

[13] N. W. Luedtke, Y. Tor, Biopolymers 2003, 70, 103-119.

[14] Y. Ye, B. Li, J. Gen. Virol. 2006, 87, 2047- 2053.

[15] P. E. Dawson, S. B. H. Kent, Annu. Rev. Biochem. 2000, 69, 923-960.

[16] S. B. H. Kent, Chem. Soc. Rev. 2009, 38, 338-351.

[17] P. E. Dawson, T. W. Muir, I. Clark-Lewis, S. B. H. Kent, Science 1994, 266, $776-779$.

[18] G. G. Kochendoerfer, D. Salom, J. D. Lear, R. Wilk-Orescan, S. B. H. Kent, W. F. DeGrado, Biochemistry 1999, 38, 11905-11913.

[19] T. M. Hackeng, J. A. Fernández, P. E. Dawson, S. B. H. Kent, J. H. Griffin, Proc. Natl. Acad. Sci. USA 2000, 97, 14074-14078.

[20] V. Y. Torbeev, S. B. H. Kent, Angew. Chem. 2007, 119, 1697-1700; Angew. Chem. Int. Ed. 2007, 46, 1667-1670.

[21] L. Z. Yan, P. E. Dawson, J. Am. Chem. Soc. 2001, 123, 526-533.

[22] D. Crich, A. Banerjee, J. Am. Chem. Soc. 2007, 129, 10064-10065.

[23] C. Haase, H. Rohde, O. Seitz, Angew. Chem. 2008, 120, 6912-6915; Angew. Chem. Int. Ed. 2008, 47, 6807-6810.

[24] J. Chen, Q. Wan, Y. Yuan, J. Zhu, S. J. Danishefsky, Angew. Chem. 2008, 120, 8649-8652; Angew. Chem. Int. Ed. 2008, 47, 8521-8524.

[25] Z. Harpaz, P. Siman, K. S. A. Kumar, A. Brik, ChemBioChem 2010, 11, $1232-1235$.

[26] Z. Tan, S. Shang, S. J. Danishefsky, Angew. Chem. 2010, 122, 9690-9693 Angew. Chem. Int. Ed. 2010, 49, 9500-9503.

[27] K. S. A. Kumar, M. Haj-Yahya, D. Olschewski, H. A. Lashuel, A. Brik, Angew. Chem. 2009, 121, 8234-8238; Angew. Chem. Int. Ed. 2009, 48, $8090-8094$.

[28] R. Yang, K. K. Pasunooti, F. Li, X.-W. Liu, C.-F. Liu, J. Am. Chem. Soc. 2009, $131,13592-13593$.

[29] J. Chen, P. Wang, J. Zhu, Q. Wan, S. J. Danishefsky, Tetrahedron 2010, 66, $2277-2283$.

[30] A. Brik, Y.-Y. Yang, S. Ficht, C.-H. Wong, J. Am. Chem. Soc. 2006, 128, 5626-5627.

[31] A. Brik, C.-H. Wong, Chem. Eur. J. 2007, 13, 5670-5675.

[32] K. S. A. Kumar, L. Spasser, L. A. Erlich, S. N. Bavikar, A. Brik, Angew. Chem. 2010, 122, 9312-9317; Angew. Chem. Int. Ed. 2010, 49, 9126-9131.

[33] R. Yang, K. K. Pasunooti, F. Li, X.-W. Liu, C.-F. Liu, Chem. Commun. 2010, 46, 7199-7201.

[34] Q. Wan, S. J. Danishefsky, Angew. Chem. 2007, 119, 9408-9412; Angew. Chem. Int. Ed. 2007, 46, 9248-9252.

[35] C. Haase, O. Seitz, Angew. Chem. 2008, 120, 1575-1579; Angew. Chem. Int. Ed. 2008, 47, 1553-1556.

[36] B. L. Pentelute, S. B. H. Kent, Org. Lett. 2007, 9, 687-690.

[37] Y. Y. Yang, S. Ficht, A. Brik, C.-H. Wong, J. Am. Chem. Soc. 2007, 129, $7690-7701$.

[38] P. Wang, L. P. Miranda, Int. J. Pept. Res. Ther. 2005, 11, 117-123.

[39] S. Ficht, R. J. Payne, R. T. Guy, C.-H. Wong, Chem. Eur. J. 2008, 14, 3620 3629.

[40] L. Z. Yan, J. P. Mayer, J. Org. Chem. 2003, 68, 1161-1162. 
[41] L. Z. Yan, P. Edwards, D. Flora, J. P. Mayer, Tetrahedron Lett. 2004, 45, 923-925.

[42] H. Li, X. Jiang, Y.-H. Ye, C. Fan, T. Romoff, M. Goodman, Org. Lett. 1999 $1,91-93$.

[43] R. von Eggelkraut-Gottanka, A. Klose, A. G. Beck-Sickinger, M. Beyermann, Tetrahedron Lett. 2003, 44, 3551-3554.

[44] A. C. Nagalingam, S. E. Radford, S. L. Warriner, Synlett 2007, 16, 2517 2520.

[45] K. S. A. Kumar, Z. Harpaz, M. Haj-Yahya, A. Brik, Bioorg. Med. Chem. Lett 2009, 19, 3870-3874.

[46] D. Bang, B. L. Pentelute, S. B. H. Kent, Angew. Chem. 2006, 118, 4089 4092; Angew. Chem. Int. Ed. 2006, 45, 3985-3988.

[47] H. Rohde, O. Seitz, Biopolymers 2010, 94, 551-559.

[48] F. Mende, O. Seitz, Angew. Chem. 2011, 123, 1266-1274; Angew. Chem. Int. Ed. 2011, 50, 1232-1240.

[49] J. B. Blanco-Canosa, P. E. Dawson, Angew. Chem. 2008, 120, 6957-6961; Angew. Chem. Int. Ed. 2008, 47, 6851-6855.

[50] R. A. Olofson, Pure Appl. Chem. 1988, 60, 1715-1725.

[51] F. Berree, Y. Malvaut, E. Marchand, G. Morel, J. Org. Chem. 1993, 58, $6022-6029$
[52] J.-S. Zheng, H.-K. Cui, G.-M. Fang, W.-X. Xi, L. Liu, ChemBioChem 2010 11, $511-515$.

[53] M. Marenchino, D. W. Armbruster, M. Hennig, Protein Expression Purif. 2009, 63, 112- 119 .

[54] C. F. Invernizzi, B. Xie, S. Richard, M. A. Wainberg, Retrovirology 2006, 3, 93-107.

[55] D. E. Fouts, H. L. True, K. A. Cengel, D. W. Celander, Biochemistry 1997 36, $13256-13262$

[56] N. Nepomniaschiy, V. Grimminger, A. Cohen, S. DiGiovanni, H. A. Lashuel, A. Brik, Org. Lett. 2008, 10, 5243-5246.

[57] G. Tuchscherer, A. Chandravarkar, M. S. Camus, J. Bérard, K. Murat, A. Schmid, R. Mimna, H. A. Lashuel, M. Mutter, Biopolymers 2007, 88, 239 252.

[58] C. Furnes, T. Arnesen, P. Askjaer, J. Kjems, A. M. Szilvay, Retrovirology 2005, 2, 39.

[59] S. J. K. Pond, W. K. Ridgeway, R. Robertson, J. Wang, D. P. Millar, Proc. Natl. Acad. Sci. USA 2009, 106, 1404-1408.

Received: January 17, 2011

Published online on $\mathbf{\square}, 0000$ 


\section{FULL PAPERS}

Winning HIV-1 Rev: The protein HIV-1 Rev plays an important role in the HIV lifecycle; however, its high tendency to aggregate has hindered several studies that aimed at deciphering better its structure and function. Two highly reproducible methods to generate this protein in large quantities, based on chemical synthesis and recombinant expression, are presented.

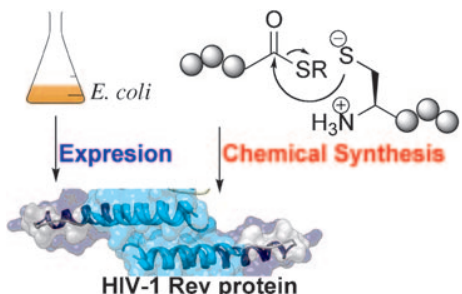

P. Siman, O. Blatt, T. Moyal, T. Danieli, M. Lebendiker, H. A. Lashuel, A. Friedler, ${ }^{*}$ A. Brik*

Chemical Synthesis and Expression of the HIV-1 Rev Protein 